\title{
Desarrollo de competencias digitales en docencia online: la asignatura Cimientos del curso de adaptación a grado en ingeniería de edificación
}

\section{Development of Digital Competencies in Online Instruction: The Case Study of the Foundation Subject for the Building Engineering Degree}

\author{
María Dolores Vivas Urías \\ Escuela de Arquitectura, Ingeniería y Diseño. Universidad Europea de Madrid, España. \\ mariadolores.vivas@universidadeuropea.es \\ Silvia Andrés Ortega \\ Escuela de Arquitectura, Ingeniería y Diseño. Universidad Europea de Madrid, España. \\ silvia.andres@universidadeuropea.es \\ Miguel Gómez Navarro \\ Escuela de Arquitectura, Ingeniería y Diseño. Universidad Europea de Madrid, España. \\ miguel.gomez@universidadeuropea.es
}

\begin{abstract}
Resumen
Las metodologías y estrategias de aprendizaje de las modalidades blended y online, representan el ambiente ideal para el desarrollo de competencias digitales ya que utilizan las Tecnologías de la Información y de la Comunicación (TIC) para producir, transmitir, distribuir y organizar conocimiento entre estudiantes. El presente artículo muestra los resultados de un estudio sobre el desarrollo de esta competencia en los estudiantes de la asignatura Cimientos del Curso de Adaptación al Grado en Ingeniera de Edificación para Arquitectos Técnicos y Aparejadores (CAGIE), de la Universidad Europea de Madrid (UEM), realizado en el curso académico 2014-2015. Los resultados obtenidos sugieren que el uso de las herramientas del campus virtual, tanto en la realización de actividades como en la interacción estudiante-estudiante y estudiante-profesor, contribuye fundamentalmente al desarrollo de dos de las áreas de la competencia digital: la comunicación y la creación de contenidos.
\end{abstract}

Palabras clave

Competencia digital, educación a distancia, semipresencial, educación superior, Ingeniería de Edificación

\begin{abstract}
Methodologies and learning strategies in blended and online instruction represent the ideal environment for the development of digital skills. Information and Communication Technology (ICT) is used to produce, transmit, distribute and organize knowledge among students. This article presents and describes the study carried out within the Foundations subject from CAGIE (Curso de Adaptación al Grado en Ingeniera de Edificación para Arquitectos Técnicos y Aparejadores) at Universidad Europea de Madrid in the 2014-15 academic period. The results suggest that the use of the tools of the virtual campus, both in the performance of activities and in student-student and student-teacher interaction, contributes mainly to the development of two of the areas of digital competence: communication and content creation.
\end{abstract}

\section{Key words}

Content curation, filtering, collaborative learning, personal learning environments. 


\section{Introducción: Las tecnologías de la Información y de la comunicación y la docencia}

El cambio tecnológico acaecido en las últimas décadas se está produciendo a un ritmo sin precedentes. El reto de formar al ciudadano del Siglo XXI, por lo tanto, supone en el ámbito de la educación superior la incorporación de competencias digitales basadas en el uso de las Tecnologías de la Información y la Comunicación (TIC) en los procesos de enseñanza-aprendizaje, que le permitan manejar la información y le proporcionen la capacidad de reflexionar, crear y solucionar problemas, a fin de generar conocimientos (UNESCO, 2009). El estudio de Redecker et al. (2010) sobre el papel de las TIC en la docencia y aprendizaje, concluyó que el uso de las tecnologías puede contribuir a una mejor aplicación de las habilidades y conocimientos a situaciones cambiantes e impredecibles, ya que la tecnología será uno de los principales impulsores del cambio en las estructuras y requisitos laborales. Pero preparar adecuadamente a los alumnos para el mundo digital implica rediseñar la propia educación, fomentar la participación colaborativa participativa y digital. Además, el uso de las TIC permite el aprendizaje en cualquier momento y en cualquier lugar lo que supone acelerar la transición entre el mundo educativo y el laboral, facilitando la reincorporación al mercado laboral de los parados de larga duración y el reciclaje permanente, ya que deberemos actualizar y mejorar nuestras capacidades a lo largo de nuestra vida (Cobo, 2012).

\section{Estudiantes digitales}

La era digital ha provocado la aparición de un nuevo perfil de estudiante, los nacidos entre 1982 y 2004, que constituyen la primera generación que ha crecido rodeada de los nuevos avances tecnológicos (Oliver y Goerke, 2007). Aunque han recibido numerosas denominaciones en los últimos años: millennials (Strauss y Howe, 2000), nativos digitales (Prensky, 2001) o generación Y (Lancaster y Stillman, 2002).

Estos autores coinciden en una serie de características comunes que los definirían, como su marcada alfabetización digital, la permanente necesidad de estar conectados, la inmediatez y la multitarea, su carácter social y su aprendizaje experiencial (Gisbert y Esteve, 2011). Prensky (2001) además afirmó la existencia de una brecha digital entre ellos y sus docentes a los que denominó inmigrantes digitales, sin embargo, con el paso del tiempo, esta taxonomía ha resultado imprecisa ya que no todos los universitarios menores de 30 años están alfabetizados digitalmente, y no todos los llamados inmigrantes digitales no lo están (Helsper y Enyon, 2009) y que esta definición a menudo no está sustentada en investigaciones ni se basa en datos empíricos, por lo que no se puede afirmar la existencia de dos generaciones totalmente diferenciadas (Corrin et al. 2010; Bullen y Morgan, 2011). White y Le Cornu (2011) proponen un paradigma alternativo, analizando las expectativas a tener en cuenta al involucrar a los estudiantes en línea y explorando las vías de interacción de visitantes y residentes digitales, estudiando aspectos relacionados a su alfabetización digital.

Frente a estas denominaciones, Gallardo (2012: 16) basándose en los estudios de Kennedy et al. (2008); Bennett, Maton y Kervin (2008); Brown y Czerniewicz (2010), propone utilizar la denominación de estudiante digital (digital learner) propuesta por

Desarrollo de competencias digitales en docencia online: la asignatura Cimientos del curso de adaptación a grado en ingeniería de edificación. María Dolores Vivas Urías, Silvia Andrés Ortega y Miguel Gómez Navarro. 
Bullen y Morgan (2011), ya que "la diversidad de estudiantes que hacen uso de la tecnología, tanto en su vida cotidiana así como en sus estudios académicos, nos indica que las generalizaciones basadas en conceptos generacionales de los nativos digitales no son útiles para discusiones sobre los cambios en estrategias de enseñanza y aprendizaje en la educación."

\section{Alfabetización y competencia digital}

La alfabetización digital es uno de los elementos fundamentales en los que se basa la formación permanente (MECD y OCDE, 2003), ya que la formación de competencias a través del uso de las TIC puede contribuir a una mejor aplicación de las habilidades y conocimientos a situaciones cambiantes e impredecibles (Esteve y Gisbert, 2011). Este concepto se ha ido desarrollando en las últimas dos décadas por lo que podemos encontrar variedad de definiciones al respecto.

Bawden (2002) indica que mientras que en una primera etapa en la literatura científica el término se relaciona con la alfabetización informática (AI), es decir, con lo que una persona necesita ser capaz de hacer con el ordenador y debe saber sobre ordenadores para poder valerse en una sociedad basada en la información (Hunter, 1983), en la década de los 90 del pasado siglo XX numerosos autores lo utilizaron como sinónimo del término alfabetización multimedia (Gilster, 1997).

En consonancia con la AI, Anderson y Weert (2002) proponen una escala de alfabetización tecnológica en cuatro niveles de enseñanza-aprendizaje relacionados con el uso de las TICs:

- descubrimiento herramientas TIC.

- aprender cómo usar las herramientas TIC.

- comprender cómo y cuándo usar las TIC para conseguir propósitos específicos.

- especializado en el uso de las herramientas TIC.

A medida que avanza el grado de conocimiento del uso de las tecnologías, aumenta la cantidad y calidad de las acciones que pueden realizarse.

En 2003 el Ministerio de Educación, Cultura y Deporte (MECD) y la Organización para la Cooperación y el Desarrollo (OCDE), se refieren a la alfabetización digital como "un sofisticado repertorio de competencias que impregnan el lugar de trabajo, la comunidad y la vida social, entre las que se incluyen las habilidades necesarias para manejar información y la capacidad de evaluar la relevancia y la fiabilidad de lo que se busca en Internet" (MECD y OCDE, 2003, p.80).

Gros y Contreras (2006, p.109) entienden este concepto en un sentido amplio considerando una serie de características como la capacidad para realizar juicios de valor informados acerca de la información que se obtenga en línea, la destreza en la lectura y la comprensión en un entorno de hipertexto dinámico y no secuencial, la destreza de construcción del conocimiento, las habilidades de búsqueda y la gestión del flujo multimedia. No es hasta 2006 cuando la competencial digital pasa a forma parte de las ocho competencias claves para el aprendizaje permanente (European Parliament and the Council, 2006), definida como una combinación de conocimientos, capacidades y actitudes, para "el uso seguro y crítico de la tecnología en la sociedad de la

Desarrollo de competencias digitales en docencia online: la asignatura Cimientos del curso de adaptación a grado en ingeniería de edificación. María Dolores Vivas Urías, Silvia Andrés Ortega y Miguel Gómez Navarro. 
información (TSI) para el trabajo, el ocio y la comunicación. Se sustenta en las competencias básicas en materia de TIC: el uso del ordenador para obtener, evaluar, almacenar, producir, presentar e intercambiar información y comunicarse y participar en redes de colaboración a través de Internet". Por lo tanto, exige el conocimiento de las principales aplicaciones informáticas así como la comprensión de las oportunidades $\mathrm{y}$ los riesgos potenciales que ofrecen Internet y la comunicación por medios electrónicos. Así mismo, esta competencia requiere una actitud crítica y reflexiva con respecto a la información disponible y un uso responsable de los medios interactivos.

En esta línea Bawden (2008) presenta una serie de habilidades, competencias y actitudes que conformarían la alfabetización digital:

- construir el conocimiento a través de diferentes fuentes.

- analizar críticamente y refutar la información extraída.

- leer y entender material dinámico y no sólo secuencial.

- tomar conciencia del valor de las herramientas tradicionales.

- conocer la importancia de las redes de personas para el asesoramiento y la ayuda.

- utilizar filtros para gestionar la información.

- publicar y comunicar información de manera sencilla y habitual

La definición de competencia digital propuesta por Calvani et al. (2009) enfatiza en la coexistencia e integración de tres dimensiones (tecnológica, cognitiva y ética) para entender el potencial que ofrecen las tecnologías permitiendo a los individuos compartir información y construir nuevos conocimientos colaborativamente. Estas tres dimensiones implican ser capaz de:

- tecnológica: explorar y hacer frente a los problemas y nuevos contextos tecnológicos de manera flexible.

- cognitiva: leer, seleccionar, interpretar y evaluar los datos y la información teniendo en cuenta su pertinencia y fiabilidad.

- ética: interactuar con otros individuos constructivamente y con sentido de la responsabilidad utilizando las tecnologías disponibles.

Ferrari (2012) por su parte, profundiza en la definición del European Parliament and the Council, indicando que esta competencia puede dividirse en varios bloques: ámbitos de aprendizaje, herramientas, áreas de competencia, formas y objetivo. Siendo cinco las áreas competencia en las que puede resumirse la competencia digital (Punie \& Brečko, 2013):

- Información: identificar, localizar, recuperar, almacenar, organizar y analizar la información digital, evaluando su finalidad y relevancia.

- Comunicación: comunicar en entornos digitales, compartir recursos a través de herramientas en línea, conectar y colaborar con otros a través de herramientas digitales, interactuar y participar en comunidades y redes; conciencia intercultural.

- Creación de contenido: crear y editar contenidos nuevos (textos, imágenes, video, etc.), integrar y reelaborar conocimientos y contenidos previos, realizar producciones artísticas, contenidos multimedia y programación informática, saber aplicar los derechos de propiedad intelectual y las licencias de uso.

Desarrollo de competencias digitales en docencia online: la asignatura Cimientos del curso de adaptación a grado en ingeniería de edificación. María Dolores Vivas Urías, Silvia Andrés Ortega y Miguel Gómez Navarro. 
- Seguridad: protección personal, protección de datos, protección de la identidad digital, uso de seguridad, uso seguro y sostenible.

- Resolución de problemas: identificar necesidades y recursos digitales, tomar decisiones a la hora de elegir la herramienta digital apropiada, acorde a la finalidad o necesidad, resolver problemas conceptuales a través de medios digitales, resolver problemas técnicos, uso creativo de la tecnología, actualizar la competencia propia y la de otros.

Para cada una de estas áreas Punie \& Brečko (2013) proponen una rúbrica que fija los indicadores del grado de dominio de las diferentes competencias que las componen, desde el nivel A Básico al nivel C Avanzado (Tablas 1 y 2):

\begin{tabular}{|c|c|c|c|}
\hline Area & \multicolumn{3}{|c|}{ Nivel } \\
\hline Área 2: Comunicación & A-Básico & B-Intermedio & C-Avanzado \\
\hline $\begin{array}{l}2.1 \text { Interacción mediante } \\
\text { nuevas tecnologías. }\end{array}$ & $\begin{array}{l}\text { Soy capaz de interactuar con } \\
\text { otros utilizando las } \\
\text { características básicas de las } \\
\text { herramientas de comunicación } \\
\text { (por ejemplo, teléfono móvil, } \\
\text { voz por IP, chat, correo } \\
\text { electrónico). }\end{array}$ & $\begin{array}{l}\text { Soy capaz de utilizar varias } \\
\text { herramientas digitales para } \\
\text { interactuar con los demás } \\
\text { incluso utilizando } \\
\text { características más avanzadas } \\
\text { de las herramientas de } \\
\text { comunicación (por ejemplo, } \\
\text { teléfono móvil, voz por IP, } \\
\text { chat, correo electrónico). }\end{array}$ & $\begin{array}{l}\text { Utilizo una amplia gama de } \\
\text { herramientas para la } \\
\text { comunicación en línea } \\
\text { (emails, chats, SMS, } \\
\text { mensajería instantánea, blogs, } \\
\text { microblogs, foros, wikis). Sé } \\
\text { seleccionar las modalidades y } \\
\text { formas de comunicación } \\
\text { digital que mejor se ajusten al } \\
\text { propósito. Soy capaz de } \\
\text { adaptar las formas y } \\
\text { modalidades de comunicación } \\
\text { según los destinatarios. Soy } \\
\text { capaz de gestionar los } \\
\text { distintos tipos de } \\
\text { comunicación que recibo. }\end{array}$ \\
\hline $\begin{array}{l}2.2 \text { Compartir información y } \\
\text { contenidos. }\end{array}$ & $\begin{array}{l}\text { Sé cómo compartir archivos y } \\
\text { contenidos a través de medios } \\
\text { tecnológicos sencillos (por } \\
\text { ejemplo, enviar archivos } \\
\text { adjuntos a mensajes de correo } \\
\text { electrónico, cargar fotos en } \\
\text { Internet, etc.) }\end{array}$ & $\begin{array}{l}\text { Sé cómo participar en redes } \\
\text { sociales y comunidades en } \\
\text { línea, en las que transmito o } \\
\text { comparto conocimientos, } \\
\text { contenidos e información. }\end{array}$ & $\begin{array}{l}\text { Soy capaz de compartir de } \\
\text { forma activa información, } \\
\text { contenidos y recursos a través } \\
\text { de comunidades en línea, } \\
\text { redes y plataformas de } \\
\text { colaboración. }\end{array}$ \\
\hline $\begin{array}{l}\text { 2.3 Participación ciudadana en } \\
\text { línea. }\end{array}$ & $\begin{array}{l}\text { Sé que la tecnología se puede } \\
\text { utilizar para interactuar con } \\
\text { distintos servicios y hago uso } \\
\text { pasivo de algunos (por } \\
\text { ejemplo, comunidades en } \\
\text { línea, gobierno, hospitales y } \\
\text { centros médicos, bancos.) }\end{array}$ & $\begin{array}{l}\text { Soy capaz de utilizar } \\
\text { activamente algunos aspectos } \\
\text { básicos de los servicios en } \\
\text { línea (por ejemplo, gobierno, } \\
\text { hospitales o centros médicos, } \\
\text { servicios electrónicos } \\
\text { ofrecidos por las } \\
\text { administraciones) }\end{array}$ & $\begin{array}{l}\text { Participo activamente en los } \\
\text { espacios en línea. Sé de qué } \\
\text { manera me puedo implicar } \\
\text { activamente en línea y soy } \\
\text { capaz de usar varios servicios } \\
\text { en línea diferentes. }\end{array}$ \\
\hline $\begin{array}{l}\text { 2.4 Colaboración mediante } \\
\text { canales digitales. }\end{array}$ & $\begin{array}{l}\text { Soy capaz de colaborar } \\
\text { mediante algunas tecnologías } \\
\text { tradicionales (por ejemplo, el } \\
\text { correo electrónico) }\end{array}$ & 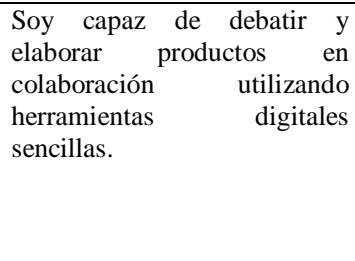 & $\begin{array}{l}\text { Soy capaz de utilizar con } \\
\text { frecuencia y con confianza } \\
\text { varias herramientas digitales y } \\
\text { diferentes medios con el fin } \\
\text { de colaborar con otros en la } \\
\text { producción y puesta a } \\
\text { disposición de recursos, } \\
\text { conocimientos y contenidos. }\end{array}$ \\
\hline
\end{tabular}

Desarrollo de competencias digitales en docencia online: la asignatura Cimientos del curso de adaptación a grado en ingeniería de edificación. María Dolores Vivas Urías, Silvia Andrés Ortega y Miguel Gómez Navarro. 


\begin{tabular}{|c|c|c|c|}
\hline Area & \multicolumn{3}{|c|}{ Nivel } \\
\hline Área 2: Comunicación & A-Básico & B-Intermedio & C-Avanzado \\
\hline 2.5 Netiqueta. & $\begin{array}{l}\text { Conozco las normas básicas } \\
\text { de conducta que rigen la } \\
\text { comunicación con otros } \\
\text { mediante } \\
\text { digitales. }\end{array}$ & $\begin{array}{l}\text { Entiendo las reglas de la } \\
\text { etiqueta en la red y soy capaz } \\
\text { de aplicarlas a mi contexto } \\
\text { personal y profesional. }\end{array}$ & $\begin{array}{l}\text { Soy capaz de aplicar varios } \\
\text { aspectos de la etiqueta en la } \\
\text { red a distintos espacios y } \\
\text { contextos de comunicación. } \\
\text { He desarrollado estrategias } \\
\text { para la identificación de las } \\
\text { conductas inadecuadas en la } \\
\text { red. }\end{array}$ \\
\hline $\begin{array}{l}\text { 2.6 Gestión de la identidad } \\
\text { digital. }\end{array}$ & $\begin{array}{l}\text { Conozco los beneficios y los } \\
\text { riesgos relacionados con la } \\
\text { identidad digital. }\end{array}$ & $\begin{array}{l}\text { Soy capaz de crear mi } \\
\text { identidad digital y de rastrear } \\
\text { mi huella digital. }\end{array}$ & $\begin{array}{l}\text { Soy capaz de gestionar } \\
\text { diferentes } \\
\text { digitales en función del } \\
\text { contexto y de su finalidad. } \\
\text { Soy capaz de supervisar la } \\
\text { información y los datos que } \\
\text { produzco a través de mi } \\
\text { interacción en línea, y sé } \\
\text { cómo proteger mi reputación } \\
\text { digital. }\end{array}$ \\
\hline
\end{tabular}

Tabla 1. Niveles de dominio del área 2 de la competencia digital (Punie \& Brečko, 2013)

\begin{tabular}{|c|c|c|c|}
\hline Area & \multicolumn{3}{|c|}{ Nivel } \\
\hline $\begin{array}{l}\text { Área 3: Creación de } \\
\text { contenidos }\end{array}$ & A-Básico & B-Intermedio & C-Avanzado \\
\hline 3.1 Desarrollo de contenidos. & $\begin{array}{l}\text { Soy capaz de crear contenidos } \\
\text { digitales sencillos (por } \\
\text { ejemplo, texto, o tablas, o } \\
\text { imágenes, oaudio, etc.) }\end{array}$ & $\begin{array}{l}\text { Soy capaz de producir } \\
\text { contenidos digitales en } \\
\text { diferentes formatos, incluidos } \\
\text { los multimedia (por ejemplo, } \\
\text { textos, tablas, imágenes, } \\
\text { audio,etc.). }\end{array}$ & $\begin{array}{l}\text { Soy capaz de producir } \\
\text { contenidos digitales en } \\
\text { formatos, plataformas y } \\
\text { entornos diferentes. Soy capaz } \\
\text { de utilizar diversas } \\
\text { herramientas digitales para } \\
\text { crear productos multimedia } \\
\text { originales. }\end{array}$ \\
\hline $\begin{array}{l}\text { 3.3 Derechos de autor y } \\
\text { licencias. }\end{array}$ & $\begin{array}{l}\text { Soy consciente de que } \\
\text { algunos de los contenidos que } \\
\text { utilizo pueden tener derechos } \\
\text { de autor. }\end{array}$ & $\begin{array}{l}\text { Conozco las diferencias } \\
\text { básicas entre las licencias } \\
\text { copyright, copyleft y creative } \\
\text { commons y soy capaz de } \\
\text { aplicarlas al contenido que } \\
\text { creo. }\end{array}$ & $\begin{array}{l}\text { Conozco cómo se aplican los } \\
\text { diferentes tipos de licencias a } \\
\text { la información y a los } \\
\text { recursos que uso y creo. }\end{array}$ \\
\hline 3.4 Programación. & $\begin{array}{l}\text { Soy capaz de modificar } \\
\text { algunas funciones sencillas de } \\
\text { software y de aplicaciones } \\
\text { (configuración básica). }\end{array}$ & $\begin{array}{l}\text { Soy capaz de realizar varias } \\
\text { modificaciones a programas y } \\
\text { aplicaciones (configuración } \\
\text { avanzada, modificaciones } \\
\text { básicas de programación). }\end{array}$ & $\begin{array}{l}\text { Soy capaz de modificar } \\
\text { programas (de código } \\
\text { abierto), cambiar o escribir el } \\
\text { código fuente, programar y } \\
\text { codificar en varios lenguajes, } \\
\text { entiendo los sistemas y las } \\
\text { funciones que hay detrás de } \\
\text { los programas. }\end{array}$ \\
\hline
\end{tabular}

Tabla 2. Nivel de dominio del área 3 de la competencia digital (Punie \& Brečko, 2013)

Desarrollo de competencias digitales en docencia online: la asignatura Cimientos del curso de adaptación a grado en ingeniería de edificación. María Dolores Vivas Urías, Silvia Andrés Ortega y Miguel Gómez Navarro. 


\section{Colaboración y aprendizaje 2.0}

La colaboración además de formar parte de una de las cinco áreas de la competencia digital (comunicación), es una forma básica de actividad humana, esencial para el desarrollo cultural. Waldegg (2002) indica que, en las diferentes definiciones de colaboración en la literatura científica, el elemento común es la idea de corresponsabilidad en la construcción del conocimiento y el compromiso compartido de los participantes (Engeström, 1992; Bruffee; 1993; Bereiter y Scardamalia, 1994; Roschelle y Teasley, 1995; Crook, 1998). Además es una característica distintiva y necesaria en el aprendizaje en entornos virtuales (Hernández, González y Muñoz, 2014). Según Cobo y Pardo (2007), los planteamientos de Johnson (1992) y de Lundvall (2002) describen el marco conceptual de los modelos de Aprendizaje 2.0, es decir:

- Aprender haciendo (learning by doing): mediante el uso de herramientas que permitan al estudiante y/o docente la lectura y la escritura en la Web, bajo el principio de ensayo-error. Este proceso de creación individual y colectiva, a la vez, promueve un proceso de aprendizaje constructivista.

- Aprender interactuando (learning by interacting): se pone el énfasis en la instancia comunicacional entre pares. Algunos ejemplos de interacción son: agregar un post en un blog o wiki, usar el chat o el correo electrónico.

- Aprender buscando (learning by searching): búsqueda de fuentes que ofrezcan información sobre un tema de estudio. Ese proceso de investigación, selección y adaptación, amplía y enriquece el conocimiento de quien lo realiza.

- Aprender compartiendo (learning by sharing): el proceso de intercambio de conocimientos y experiencias permite a los educandos participar activamente de un aprendizaje colaborativo, ya que tener acceso a la información, no significa aprender.

El Aprendizaje 2.0 por tanto, enlaza con la idea analizada por Gibbons et al. (1994) de conocimiento socialmente distribuido, ya que se genera un conocimiento intercambiable, acumulativo, colaborativo, que puede ser compartido, transferido y convertido en un bien público (Cobo y Pardo, 2007).

Sfard (1998) examinó la evolución del papel del docente a través del uso de las tecnologías de la información, identificando dos modelos de enseñanza y aprendizaje:

- modelo de asimilación: el enfoque de los objetivos de aprendizaje se centra en la adquisición de conocimientos preestablecidos y en el desarrollo de la comprensión de determinados conceptos. El alumno interactúa con contenido preestablecido y el papel del docente es proporcionar, sugerir y aclarar conocimiento y conceptos.

- modelo de participación: el docente es un facilitador y el enfoque de actividades de aprendizaje consiste en formar parte de una comunidad de práctica, recibiendo y contribuyendo al mismo tiempo en el proceso de aprendizaje. Este marco de colaboración (transformación), pone en relieve el desarrollo del pensamiento individual y la construcción del significado.

Desarrollo de competencias digitales en docencia online: la asignatura Cimientos del curso de adaptación a grado en ingeniería de edificación. María Dolores Vivas Urías, Silvia Andrés Ortega y Miguel Gómez Navarro. 
Para crear estos entornos de aprendizaje, es necesaria la utilización de los entornos virtuales de aprendizaje (EVA), más habitualmente conocidos como aulas o campus virtuales, que dotan al profesor de herramientas suficientes para la transmisión de conocimientos y desarrollo de competencias y habilidades (Blanco, 2009). Si el docente crea las condiciones necesarias para que el estudiante pueda aprender frente a los estímulos del ambiente de aprendizaje, pasa a ser un asesor y facilitador (Johnson, 1992), mientras que los estudiantes se convierten en actores de cambio con habilidades y modos de trabajo innovadores. Pero para que esto suceda, debe darse una interacción constante entre estudiante-contenido, entre estudiante-profesor, así como entre estudiante-estudiante (Anderson y Garrison, 1998).

La interacción en entornos virtuales de enseñanza-aprendizaje es señalada por numerosos estudios como un factor decisivo para el éxito del aprendizaje (Zhao et al., 2005; Davidson-Shivers, 2009; Baker, 2010). Pero la colaboración entre estudiantes no sucede de forma espontánea (Kirschner, et al.2008) y se necesita un proceso de aprendizaje. Como señalan Noguera y Gros (2014) la colaboración en entornos virtuales añade aspectos de complejidad relacionados con la gestión y la comunicación entre los grupos. En este contexto, el papel del profesor debe centrarse en ofrecer herramientas para la gestión de la colaboración, dar pautas, guiar, ayudar en la planificación y la organización, prevenir, fomentar una actitud positiva de los estudiantes hacia el aprendizaje colaborativo, dinamizar las discusiones, motivar la participación y realizar un seguimiento visible de los estudiantes.

\section{Evaluación de la competencia digital en educación superior}

En los últimos años se han desarrollado distintos instrumentos para la evaluación de la competencia digital, siendo las principales alfabetizaciones evaluadas la tecnológica y la informacional (Gisbert y Esteve, 2013). Consisten fundamentalmente en cuestionarios entre los que cabe destacar el International Computer Driving License (ICDL), principal programa de certificación de conocimientos básicos informáticos (Calvani et al. 2009), y el iSkills que es una prueba para evaluar el pensamiento crítico y las habilidades para resolver problemas que poseen los estudiantes en un entorno digital (Katz, 2007). Ambas utilizan la simulación de un entorno tecnológico para medir principalmente los conocimientos y las habilidades del usuario. A nivel nacional se ha desarrollado el INCOTIC o Inventario de Competencias TIC (Gisbert, Espuny, \& González, 2011), herramienta de evaluación autodiagnóstica para alumnos de primer año. Se trata de un cuestionario que consta de dos partes: identificación, recurso y usos de las TIC y competencia digital y actitudes TIC. El objetivo es que los resultados permitan evaluar inicialmente al alumnado y que el profesor se centre en diseñar el proceso formativo.

A partir del INCOTIC, Centeno y Cubo (2013) elaboran su propia herramienta, un cuestionario basado en una escala de respuesta tipo Likert de 5 puntos, compuesto por 66 items agrupados en las siguientes dimensiones: datos de identificación, disponibilidad y uso de recursos TIC, conocimiento de herramientas y recursos TIC, alfabetización tecnológica, habilidades en TIC y actitudes TIC. Un análisis crítico de los resultados sugiere la necesidad de que las actividades de capacitación tecnológica que se planteen abandonen la formación instrumental y se centren en lograr que los estudiantes utilicen las TIC como medio de construcción de su propio conocimiento.

Desarrollo de competencias digitales en docencia online: la asignatura Cimientos del curso de adaptación a grado en ingeniería de edificación. María Dolores Vivas Urías, Silvia Andrés Ortega y Miguel Gómez Navarro. 


\section{Competencia digital en la UEM}

El modelo académico de la Universidad Europea de Madrid (UEM) apuesta por una formación integral del estudiante a través de la adquisición y desarrollo de competencias personales y profesionales que le permitan incorporarse al mundo laboral en condiciones óptimas. Dentro de su modelo pedagógico, en 2012 se seleccionaron 18 competencias transversales comunes a todos los grados de la UEM (Velasco, García y Terrón, 2012) entre las que se encuentran el aprendizaje autónomo, la capacidad de análisis y síntesis, la conciencia de los valores éticos, la gestión de la información, la responsabilidad, el trabajo en equipo y la utilización de las tecnologías de la información y las comunicaciones (TIC).Esta última se define como la capacidad para utilizar eficazmente las tecnologías de la información y las comunicaciones como herramienta para la búsqueda, procesamiento y almacenamiento de la información, así como para el desarrollo de habilidades comunicativas. Su rúbrica se muestra en la Tabla 3.

Según la encuesta realizada en 2015 (Vivas et al. 2015) a 28 profesores del Departamento de Tecnología y Gestión de la Edificación de la Escuela de Arquitectura, Ingeniera y Diseño de la UEM, solo un 30,8\% de los profesores encuestados evalúa todos los indicadores del grado de desarrollo de la competencia transversal "Utilización de las TIC". Un 23,1\% evalúa alguno de estos indicadores y el 38,5\% de los profesores que no evalúan esta competencia creen que debería adquirirse de manera autónoma.

\begin{tabular}{|c|c|c|c|c|}
\hline Competencia & \multicolumn{4}{|c|}{ Indicadores de logro } \\
\hline $\begin{array}{l}\text { UEM-CT18 } \\
\text { Utilización de las TIC }\end{array}$ & 1 & 2 & 3 & 4 \\
\hline $\begin{array}{l}\text { CT18 (1): Gestión de } \\
\text { archivos y carpetas }\end{array}$ & $\begin{array}{l}\text { Tiene dificulta- des } \\
\text { para gestionar archivos } \\
\text { (nombres, extensiones, } \\
\text { ubicación...). }\end{array}$ & $\begin{array}{l}\text { No crea estructuras de } \\
\text { carpetas para } \\
\text { almacenar la } \\
\text { información. }\end{array}$ & $\begin{array}{l}\text { Crea y utiliza una } \\
\text { estructura de carpetas } \\
\text { adecuada. }\end{array}$ & $\begin{array}{l}\text { Crea, modifica y } \\
\text { adapta las estructuras } \\
\text { de carpetas a sus } \\
\text { necesidades. }\end{array}$ \\
\hline $\begin{array}{l}\text { CT18 (2): Autonomía } \\
\text { en el uso de las } \\
\text { aplicaciones } \\
\text { informáticas. }\end{array}$ & $\begin{array}{l}\text { Solo es capaz de } \\
\text { manejar las } \\
\text { aplicaciones si es } \\
\text { completamente guiado } \\
\text { por otros. }\end{array}$ & $\begin{array}{l}\text { Necesita consultar a } \\
\text { otros constantemente } \\
\text { cuando usa } \\
\text { aplicaciones } \\
\text { informáticas. }\end{array}$ & $\begin{array}{l}\text { Utiliza la función de } \\
\text { ayuda de las } \\
\text { aplicaciones para } \\
\text { resolver sus dudas. }\end{array}$ & $\begin{array}{l}\text { Utiliza la función de } \\
\text { ayuda de las } \\
\text { aplicaciones. Consulta } \\
\text { foros, expertos, etc. } \\
\text { para resolver sus } \\
\text { dudas. }\end{array}$ \\
\hline $\begin{array}{l}\text { CT18 (3): Uso de } \\
\text { correo electrónico }\end{array}$ & $\begin{array}{l}\text { No utiliza correo } \\
\text { electrónico, o no lo } \\
\text { utiliza con la } \\
\text { frecuencia necesaria. }\end{array}$ & $\begin{array}{l}\text { Envía y recibe correos } \\
\text { electrónicos, pero con } \\
\text { un formato in-correcto } \\
\text { (omite firma, asunto, } \\
\text { lenguaje in-correcto, } \\
\text { etc.). }\end{array}$ & $\begin{array}{l}\text { Envía y recibe correos } \\
\text { electrónicos, con un } \\
\text { formato correcto } \\
\text { (incluye firma, asunto, } \\
\text { lenguaje adecuado, } \\
\text { etc.). } \\
\text { Utiliza listas de } \\
\text { distribución ya creadas. }\end{array}$ & $\begin{array}{l}\text { Utiliza correctamente } \\
\text { opciones avanzadas: } \\
\text { crea grupos y listas de } \\
\text { distribución. } \\
\text { Organiza los mails en } \\
\text { carpetas y utiliza } \\
\text { filtros. } \\
\text { Configura el aspecto de } \\
\text { la aplicación de correo } \\
\text { conforme a sus } \\
\text { necesidades. }\end{array}$ \\
\hline
\end{tabular}

Desarrollo de competencias digitales en docencia online: la asignatura Cimientos del curso de adaptación a grado en ingeniería de edificación. María Dolores Vivas Urías, Silvia Andrés Ortega y Miguel Gómez Navarro. 


\begin{tabular}{|c|c|c|c|c|}
\hline Competencia & \multicolumn{4}{|c|}{ Indicadores de logro } \\
\hline $\begin{array}{l}\text { UEM-CT18 } \\
\text { Utilización de las TIC }\end{array}$ & 1 & 2 & 3 & 4 \\
\hline $\begin{array}{l}\text { CT18 (4): Localización } \\
\text { de la información } \\
\text { necesaria a través de } \\
\text { Internet }\end{array}$ & $\begin{array}{l}\text { No utiliza buscadores } \\
\text { ni es capaz de buscar } \\
\text { información en una } \\
\text { página dada. }\end{array}$ & $\begin{array}{l}\text { Sólo utiliza buscadores } \\
\text { genéricos y opciones } \\
\text { básicas de búsqueda. }\end{array}$ & $\begin{array}{l}\text { Utiliza buscadores } \\
\text { específicos y navega } \\
\text { por las páginas para } \\
\text { buscar información en } \\
\text { ellas. }\end{array}$ & $\begin{array}{l}\text { Es capaz de detectar } \\
\text { las fuentes de } \\
\text { información necesarias } \\
\text { y buscar en ellas. } \\
\text { Utiliza opciones } \\
\text { avanzadas de los } \\
\text { buscadores }\end{array}$ \\
\hline
\end{tabular}

Tabla 3. Rúbrica de la competencia Utilización de las TIC (Velasco, García y Terrón, 2012)

\section{La asignatura Cimientos del Curso de Adaptación a Grado en Ingeniería de Edificación (CAGIE)}

A continuación se describe el contexto en el que se han utilizado las TIC en una asignatura que se imparte en el del Curso de Adaptación a Grado en Ingeniería de Edificación (CAGIE) de la Universidad Europea de Madrid (UEM). Esta descripción abarca tanto aspectos metodológicos como aspectos relacionados con la evaluación que permiten entender mejor las aportaciones del uso de las TIC.

La asignatura Cimientos pertenece al cuarto curso del Grado en Ingeniería de Edificación (GIE) tiene como objetivo profundizar en el conocimiento de las técnicas del suelo y en el diseño de las cimentaciones. Se trata de una materia técnica, compleja, con gran componente de cálculo numérico y la única perteneciente al área de Estructuras de Edificación que se ha estado impartiendo en modalidad online en un grado en España. Además, es idéntica en el CAGIE, que desde 2010-2011 se imparte en tres modalidades de estudio: online (e-learning), semipresencial (blended learning) y presencial (face-to-face).

Esta materia sigue el modelo pedagógico UEM Personal (Cruz, Lara y Redondo, 2010), basado en la flexibilidad, la personalización del aprendizaje y la interacción (entre estudiantes, estudiante y profesor, y entre estudiante y contenido). Es obligatoria y se divide en 6 créditos ECTS que se organizan en torno a las siguientes actividades y dedicación del estudiante:

\begin{tabular}{|l|l|}
\hline \multicolumn{1}{|c|}{ MÓDULO 6 ECTS (150 horas) } & DEDICACIÓN ALUMNO TRIMESTRAL \\
\hline - Actividades individuales (2 ECTS) & 50 horas \\
\hline $\begin{array}{l}\text { Actividades colaborativas y trabajo en } \\
\text { grupo integrador (1 ECTS) }\end{array}$ & 25 horas \\
\hline - Evaluación y tutorías (1 ECTS) & 25 horas \\
\hline Trabajo autónomo (2 ECTS) & 50 horas \\
\hline TOTAL & $\mathbf{1 5 0}$ horas \\
\hline
\end{tabular}

Desarrollo de competencias digitales en docencia online: la asignatura Cimientos del curso de adaptación a grado en ingeniería de edificación. María Dolores Vivas Urías, Silvia Andrés Ortega y Miguel Gómez Navarro. 
Figura 1. Actividades/dedicación del estudiante (Cruz, Lara y Redondo, 2010)

Los estudiantes del CAGIE responden a dos tipos de perfiles: junior y senior (Castaño y Garín, 2012). Los estudiantes junior son aquellos que han obtenido su diplomatura recientemente deciden continuar sus estudios (digital learner), mientras que el perfil de alumno senior corresponde al de profesionales de larga trayectoria, es decir adultos profesionales que cuentan con un alto grado de motivación hacia los programas formativos que deciden emprender, sofisticados recursos de aprendizaje basados en su experiencia y competencias de planificación del tiempo y autogestión altamente desarrolladas. Necesitan que el aprendizaje sea significativo, acorde a sus expectativas (Knowles, 1980; Learreta, Cruz y Benito, 2012).

En la práctica docente de la materia se utilizan metodologías activas, especialmente el aprendizaje cooperativo y el aprendizaje basado en problemas. La asignatura se organiza en seis unidades de aprendizaje (UA) distintas, sucesivas en el tiempo y lineales en los conocimientos, de manera que es necesario superar cada una de ellas para entender correctamente la siguiente. Cada una de estas unidades se estudia en dos semanas e incluye tres tipos de actividades relacionadas con la aplicación y transferencia de lo aprendido, asociadas a una o varias competencias incluidas en el currículum de la materia (Redondo, 2012):

- Individuales: están diseñadas para promover el aprendizaje autónomo, siendo responsabilidad del alumno desarrollarlas adecuadamente y presentarlas en los plazos establecidos.

- Colaborativas: tienen el objetivo de generar un ambiente de aprendizaje participativo y establecer la cohesión del grupo.

- Trabajo en grupo integrador: están diseñadas para objetivo de integrar los conocimientos y desarrollar la competencia de trabajo en equipo. Se realizan en grupos pequeños y pueden llevarse a cabo a lo largo de la materia o en la última unidad de aprendizaje.

A lo largo del trimestre se programan tres actividades individuales y una colaborativa en cada UA de la 1 a 5 que se desarrollan el apoyo de las herramientas del campus virtual. En las actividades aplicativas individuales se utiliza un sistema de evaluación a automática (Barberá, 2006) mediante cuestionarios, dos evaluables (uno teórico y otro práctico) y uno de autoevaluación, que deben realizarse en el campus virtual de la asignatura siempre después de leer la teoría y los recursos complementarios correspondientes y de haber planteado en el foro de la unidad las dudas correspondientes. Para garantizar que el nivel de dificultad de los cuestionarios sea uniforme y que no existen dos cuestionarios iguales, los cuestionarios evaluables se generan aleatoriamente a partir de una base de preguntas creada por el equipo docente. En los prácticos, además de una extensa base de preguntas calculadas organizadas por categorías, se emplea un amplio rango de valores numéricos que aseguran la autonomía de las preguntas.

La actividad colaborativa consiste en la realización de un trabajo integrador el proyecto de cimentación de la estructura de un edificio. Se divide en cinco prácticas, una por UA

Desarrollo de competencias digitales en docencia online: la asignatura Cimientos del curso de adaptación a grado en ingeniería de edificación. María Dolores Vivas Urías, Silvia Andrés Ortega y Miguel Gómez Navarro. 
de la 1 a la 5, que constan de dos fases: autoevaluación y colaboración. La fase de autoevaluación consiste en la aplicación de los conocimientos adquiridos a la resolución de una práctica cuya solución numérica se proporciona a través de un cuestionario de autoevaluación. La fase colaborativa, que se realiza en grupos de un máximo de tres alumnos, consiste en la elaboración de una memoria explicativa de los pasos seguidos en la resolución de la práctica mediante el uso de una herramienta Wiki y/o un foro privado (Sala de trabajo de grupo), ya que para poder evaluar esta tarea a los estudiantes debe quedar acreditada su autoría (Zapata, 2010).

Este modelo pedagógico que sigue la asignatura (Redondo, 2012) está basado en la interacción y la colaboración frecuente entre profesor y estudiante, y entre estudiantes, por lo que el profesor debe:

- pautar el estudio de las unidades de aprendizaje, resolver dudas, ofrecer indicaciones para realizar actividades y apoyar a los estudiantes para mejorar la comprensión de la asignatura.

- promover la participación y la cohesión del grupo presentando la asignatura, dinamizando los foros e impartiendo seminarios virtuales (videoconferencias).

- realizar un seguimiento visible, tutorizando la realización de actividades y contactando con los alumnos que no estén siguiendo el ritmo de aprendizaje de la materia.

- evaluar al estudiante ofreciendo retroalimentación cuantitativa y cualitativa a la hora de corregir y calificar actividades.

De este modo, el docente realiza un seguimiento continuado de los estudiantes, respondiendo a las dudas planteadas en los foros de cada UA y a las enviadas por correo electrónico en menos de veinticuatro horas. En las actividades individuales prácticas se pide a los alumnos que revisen las preguntas que han fallado, y en caso de no encontrarlo, que envíen por correo electrónico el desarrollo de los ejercicios para poder realizar una corrección manual. En el caso de las actividades teóricas si los alumnos no están de acuerdo con algunas de las respuestas, se someten a debate en los foros de dudas. En las actividades colaborativas cada vez que un miembro del grupo comparte una nueva información en la wiki o en la sala de grupo, recibe una corrección por parte del profesor a través del mismo medio utilizado. Una vez finalizado el plazo de entrega, la calificación de la actividad se realiza mediante una tarea creada a tal efecto en el campus virtual, siempre acompañada de comentarios adicionales.

Además, quincenalmente, siempre antes de la fecha de entrega de las actividades propuestas en cada unidad, se realiza un seminario o tutoría grupal virtual utilizando la herramienta Blackboard Collaborate, en el que los estudiantes pueden resolver dudas en tiempo real. La fecha y horario de la videoconferencia se fijan mediante una herramienta de consulta en el campus virtual.

La calificación final de la asignatura es el resultado de una evaluación continua y formativa, resultado de la suma ponderada de:

- La calificación resultante de una prueba objetiva (25\%).

Desarrollo de competencias digitales en docencia online: la asignatura Cimientos del curso de adaptación a grado en ingeniería de edificación. María Dolores Vivas Urías, Silvia Andrés Ortega y Miguel Gómez Navarro.

Página 12 de 29 
- La calificación resultante de las actividades individuales (18\% cuestionarios teóricos y $42 \%$ cuestionarios prácticos).

- La calificación resultante de la realización de las actividades colaborativas (15\%).

El estudiante supera la asignatura en convocatoria ordinaria si su calificación media final es igual o mayor de 5,0 y además, la nota de la prueba presencial es igual o mayor de 3,0. La realización de la prueba presencial tiene carácter obligatorio para aprobar la asignatura, ya que se plantea como una herramienta de acreditación de la autoría de los cuestionarios evaluables teóricos y prácticos (Zapata, 2010).

\section{Metodología de la investigación}

Las metodologías y estrategias de aprendizaje de las modalidades blended y online, representan el ambiente ideal para el desarrollo de competencias digitales ya que utilizan las Tecnologías de la Información y de la Comunicación (TIC) para producir, transmitir, distribuir y organizar conocimiento entre individuos. Con el objetivo de analizar si la metodología empleada en la asignatura de Cimientos del CAGIE, independientemente de su modalidad de impartición, propicia el desarrollo de la competencia digital por parte de los estudiantes, entendida el uso de las TIC como medio de construcción de su propio conocimiento (Centeno y Cubo, 2013), se ha realizado un estudio de descriptivo basado en encuestas realizadas ex pos facto (Kerlinger y Lee, 1964) a los estudiantes de la asignatura Cimientos del curso 20142015 del CAGIE (Gómez et al. 2015).

Una vez finalizado el curso y firmadas las actas de notas se realizó una encuesta al universo de estudio compuesta por 20 items agrupados en las siguientes dimensiones: datos de identificación, percepción el desarrollo de competencias transversales, conocimiento previo y nivel de pericia de las herramientas TIC utilizadas en el campus virtual, y percepción sobre el grado de utilidad de estas herramientas.

El primer bloque de preguntas estaba compuesto por siete preguntas cerradas relativas a la información general sobre el sujeto, con el objetivo de analizar si variables como la edad, la modalidad de estudio elegida, la experiencia profesional previa o la motivación influyeron en el proceso de aprendizaje. Las variables que se pretendían estudiar eran:

- Edad y sexo

- Modalidad en la que realizó el curso.

- Experiencia laboral previa.

- Experiencia profesional anterior al curso relaccionada con la materia de estudio.

- Simultaneidad del curso con actividad profesional

- Simultaneidad del curso con otros estudios

- Motivación a la hora de hacer el curso.

El segundo bloque estaba formado por cinco preguntas cerradas relativas a la relación del sujeto con las nuevas tecnologías en la docencia (Campus Virtual y sus herramientas) antes de la realización del Curso de Adaptación a Grado en Ingeniería de Edificación (CAGIE). El objetivo era analizar si las dificultades encontradas por los alumnos en su proceso de adaptación a las herramientas utilizadas en el Campus Virtual

Desarrollo de competencias digitales en docencia online: la asignatura Cimientos del curso de adaptación a grado en ingeniería de edificación. María Dolores Vivas Urías, Silvia Andrés Ortega y Miguel Gómez Navarro. 
(CV) influyeron en el proceso de aprendizaje. Las variables a que se pretendían estudiar eran:

- Uso de Internet.

- Experiencia previa en cursos con plataforma virtual.

- Experiencia previa en cursos a distancia.

- Nivel de conocimiento previo y nivel de pericia en el uso de las herramientas del campus virtual: foros, wikis, teleconferencias, cuestionarios,...

- Nivel de dificultad en el uso de las herramientas del campus virtual.

En el tercer bloque se recogía la percepción de los alumnos acerca de la organización de la asignatura y de la utilidad de las herramientas utilizadas en el campus virtual con el objetivo de determinar si estas facilitan la comunicación tanto con el profesor como con otros estudiantes, la colaboración entre alumnos y la construcción de conocimiento.

Para ello, se decidió utilizar como instrumento de evaluación una escala de actitud tipo Likert (1932) de cuatro ítems. Aunque muchos investigadores se inclinan por escalas con cinco o siete puntos, ya que según aumenta el número de grados de la escala lo hace también la fiabilidad (Alaminos y Castejón, 2006), se desechó utilizar una escala de respuesta de Likert de cinco ítems para evitar que los encuestados no usaran los valores extremos de las categorías en un intento de complacer o ayudar al entrevistador, o bien de omitir respuestas que socialmente serían reprobables, fenómeno denominado central tendency bias (Garland, 1991). Se pidió a los estudiantes encuestados que mostraran su grado de acuerdo o desacuerdo con una serie de afirmaciones en relación a:

- la organización de la asignatura.

- los foros de dudas y salas de trabajo de grupo.

- las wikis.

El último bloque correspondía a la autoevaluación del grado de desarrollo alcanzado por los alumnos en cinco competencias transversales (aprendizaje autónomo, capacidad de análisis y síntesis, capacidad de aplicar los conocimientos a la práctica, razonamiento crítico y responsabilidad) después de haber cursado la materia. Las competencias seleccionadas para este estudio fueron las mismas que se habían elegido en 2014 dentro del proyecto de investigación CAGIE C+C (Gómez et al., 2015) como las que más se desarrollaban en el CAGIE a partir de los resultados de una encuesta realizada a 22 profesores de este curso de adaptación.

Para evaluar la percepción de los alumnos sobre el desarrollo de estas competencias transversales, se pedía a los estudiantes encuestados que mostraran su grado de acuerdo o desacuerdo con una serie de afirmaciones, que correspondían con el máximo dominio de los indicadores de logro (Rué, 2007) definidos en la rúbrica UEM de la competencia a evaluar (Tobón, 2006; Velasco, García y Terrón, 2012) (Tabla 4) de acuerdo con una escala de actitud tipo Likert (1932) de cuatro ítems. De este modo, el grado de dominio 1 (competencia no desarrollada) se correspondería con la respuesta "En total desacuerdo", mientras que el grado de dominio 4 (competencia 100\% desarrollada) se correspondería con la respuesta "Totalmente de acuerdo".

El cuestionario de encuesta, generado con la ayuda del software SurveyMonkey (SurveyMonkey, 2015), se envió a través de un mensaje publicado en el Foro General

Desarrollo de competencias digitales en docencia online: la asignatura Cimientos del curso de adaptación a grado en ingeniería de edificación. María Dolores Vivas Urías, Silvia Andrés Ortega y Miguel Gómez Navarro.

Página 14 de 29 
del campus virtual de la asignatura Cimientos al universo de estudio, formado por los 118 alumnos del CAGIE que cursaron la materia en la Escuela de Arquitectura, Ingeniería y Diseño de la UEM durante el curso académico 2014-2015. Estos estudiantes pertenecían a los grupos online de octubre $(\mathrm{N}=67)$ y diciembre $(\mathrm{N}=25)$, y al grupo semipresencial de octubre $(\mathrm{N}=26)$, lo que supone un $77,97 \%$ de alumnos online frente a un $22,03 \%$ semipresenciales.

El 11 de abril de 2015 se publicó en los grupos online y el 10 de mayo de 2015 en el grupo semipresencial. A los siete días se envió un segundo mensaje a modo de recordatorio. La encuesta estuvo disponible en cada grupo dos semanas. Todos los participantes fueron informados sobre el objetivo del estudio, sus respuestas se trataron de forma confidencial y la participación fue totalmente voluntaria.

\begin{tabular}{|c|c|}
\hline Competencias transversales & Indicadores de logro \\
\hline \multirow[t]{4}{*}{ Aprendizaje Autónomo } & Aplicar conocimientos a la práctica \\
\hline & Utilizar las estrategias más convenientes a cada actividad \\
\hline & Detectar mis errores y aprender de ellos \\
\hline & Aprender por mí mismo \\
\hline \multirow[t]{4}{*}{ Capacidad de Análisis y Síntesis } & Identificar los elementos más significativos de un tema \\
\hline & $\begin{array}{l}\text { Exponer los elementos que constituyen el todo, relacionándolos de } \\
\text { manera eficaz }\end{array}$ \\
\hline & Determinar que tienen en común varios ejemplos de casos reales \\
\hline & Integrar todas las ideas y elementos relevantes \\
\hline \multirow{5}{*}{$\begin{array}{l}\text { Capacidad para aplicar conocimientos } \\
\text { a la práctica }\end{array}$} & Realizar deducciones pasando de lo genérico a lo concreto \\
\hline & Aplicar el conocimiento adecuado en casos prácticos \\
\hline & $\begin{array}{l}\text { Encontrar la correspondencia entre un nuevo problema y un ejemplo real } \\
\text { conocido }\end{array}$ \\
\hline & Determinar que tienen en común varios casos reales \\
\hline & Identificar los conocimientos implicados en la resolución de un problema \\
\hline \multirow[t]{4}{*}{ Razonamiento Crítico } & $\begin{array}{l}\text { Considerar todas las posibles perspectivas de aproximación a un } \\
\text { problema y documentarlas correctamente }\end{array}$ \\
\hline & $\begin{array}{l}\text { Elaborar una generalización válida basándome en conclusiones derivadas } \\
\text { del análisis de un problema }\end{array}$ \\
\hline & Seleccionar la mejor solución a un problema, argumentándola \\
\hline & Emitir juicios de valor propios aplicándolos convenientemente \\
\hline \multirow[t]{2}{*}{ Responsabilidad } & Entregar las actividades antes del plazo de entrega \\
\hline & Realizar el $100 \%$ de las tareas obligatorias solicitadas \\
\hline
\end{tabular}

Desarrollo de competencias digitales en docencia online: la asignatura Cimientos del curso de adaptación a grado en ingeniería de edificación. María Dolores Vivas Urías, Silvia Andrés Ortega y Miguel Gómez Navarro. 


\begin{tabular}{|l|l|}
\hline Competencias transversales & Indicadores de logro \\
\hline \multirow{3}{*}{} & Implicarme al máximo en el cumplimiento de las tareas \\
\cline { 2 - 2 } & Preocuparme para que el trabajo sea de gran calidad \\
\hline
\end{tabular}

Tabla 4. Indicadores de logro de las competencias transversales evaluadas (Velasco, García y Terrón, 2012)

\section{Resultados del estudio}

Durante el período de tiempo que estuvo disponible la encuesta, se registraron 58 accesos válidos, que conforman la muestra de estudio, ya que el 100\% de los alumnos que comenzaron la encuesta la finalizaron. Para este tamaño de muestra con un nivel de confianza del $95 \%$ en la estimación, correspondiendo a un valor Z (distribución normal tipificada) de 1,96, el margen de error es del 9,3\% (Bartlett, Kotrlik y Higgins, 2001; Cochran, 1977).

Un $60,4 \%$ de los participantes en las encuesta eran hombres frente a un 39,6\% de mujeres. El 74,1\% de los encuestados pertenecía a la modalidad online ( $\mathrm{N}=28$ al grupo de octubre y $\mathrm{N}=14$ al grupo de diciembre), mientras que un 25,9\% realizó el curso en modalidad semipresencial ( $\mathrm{N}=15)$ (Figura 2), siendo estos últimos los alumnos más participativos si tenemos en cuenta el número de alumnos del universo de estudio.

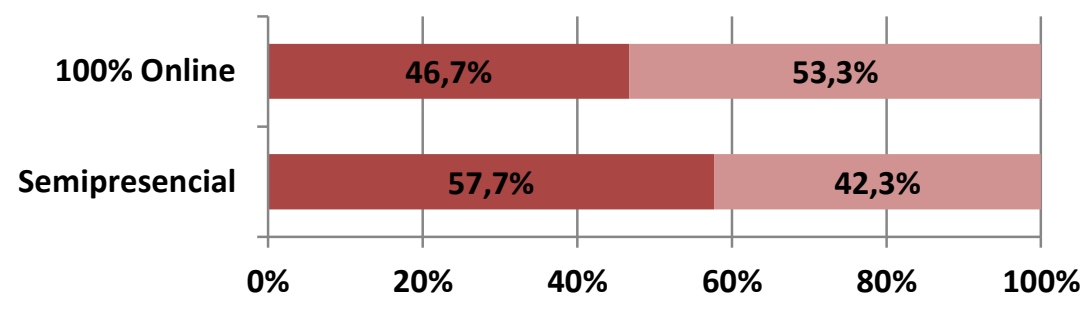

- han participado en la encuesta no han realizado la encuesta

Figura 2. Participación por modalidad de estudio curso 2014-2015

Más de la mitad de los participantes (59\%) tenían entre 30 y 39 años, mientras que los menores de 30 años suponen el $24 \%$ de la muestra (Figura 3).

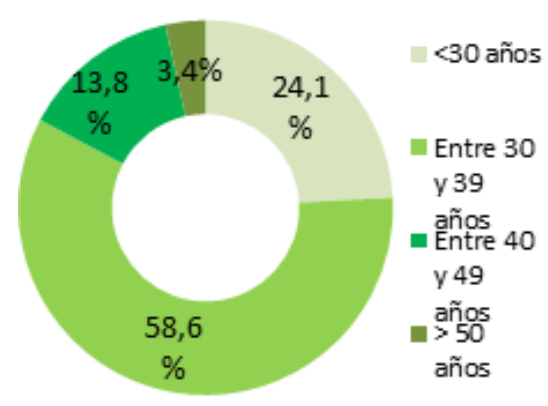

Figura 3. Edad de la muestra

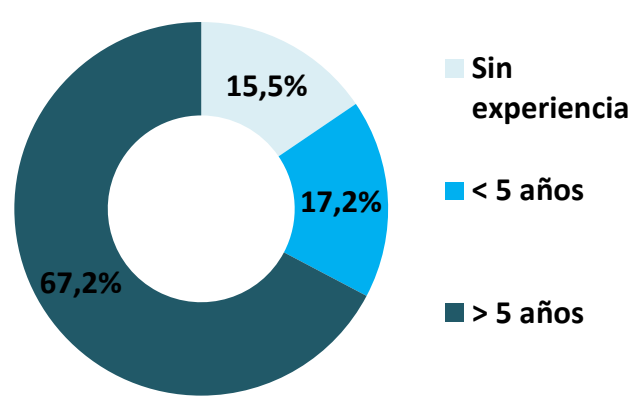

Figura 4. Experiencia laboral previa.

Desarrollo de competencias digitales en docencia online: la asignatura Cimientos del curso de adaptación a grado en ingeniería de edificación. María Dolores Vivas Urías, Silvia Andrés Ortega y Miguel Gómez Navarro. 
El 89,7\% de los encuestados compatibilizó los estudios del CAGIE con su actividad profesional, mientras que el $67,2 \%$ de los encuestados tenía una experiencia profesional previa superior a 5 años (Figura 4). En solo el 7\% de los casos esta experiencia previa estaba relacionada con la asignatura.

Antes de la realización del CAGIE, casi la totalidad de los encuestados accedía a Internet para consultar su correo electrónico, y más de un $70 \%$ lo hacía para buscar información y conectarse a redes sociales y/o profesionales (Figura 5).

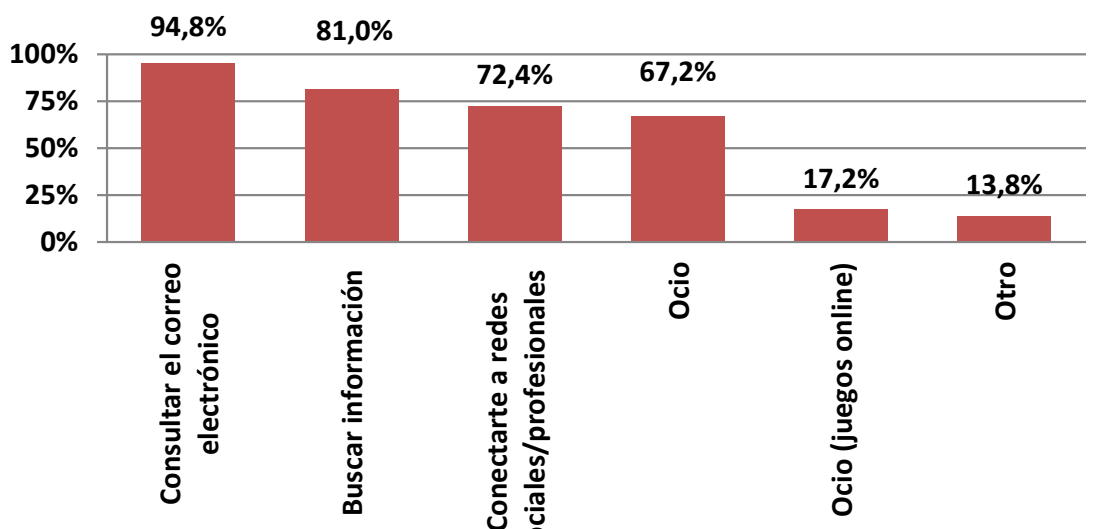

Figura 5. Uso de Internet que hacen los alumnos del curso 2014-2015

Con anterioridad al CAGIE, el $67 \%$ de los participantes había realizado algún curso a distancia y un 55\% tenía experiencia previa en el uso de la plataforma virtual. Un 79,3\% de los participantes encontró fácil el manejo del campus virtual (CV) (Figura 6).

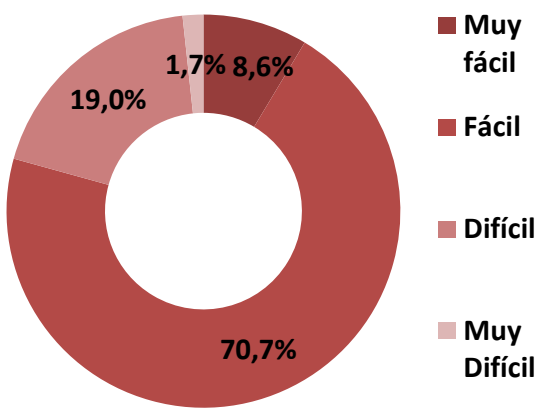

Figura 6. Nivel de dificultad en el manejo del CV

Se han extraído del campus virtual los datos cuantitativos acerca del número de mensajes que se han intercambiado en los distintos foros, el número de foros creados y el número de wikis generadas en cada uno de los grupos de la asignatura del curso académico 2014-2015: 


\begin{tabular}{|l|c|c|c|c|}
\hline \multicolumn{1}{|c|}{ Grupos } & $\mathbf{N}^{\mathbf{o}}$ alumnos & $\mathbf{N}^{\mathbf{o}}$ mensajes & $\mathbf{N}^{\mathbf{o}}$ Foros & $\mathbf{N}^{\mathbf{o}}$ Wikis \\
\hline Grupos Online Octubre 2014-2015(OO14-15) & 67 & 2304 & 33 & 121 \\
\hline Online Diciembre 2014-2015(OD14-15) & 25 & 875 & 19 & 67 \\
\hline Semipresencial Octubre 2014-2015 (S14-15) & 26 & 677 & 17 & 47 \\
\hline
\end{tabular}

Tabla 5. Nivel de pericia previa en el uso de herramientas del Campus Virtual

Respecto al nivel previo de pericia en el manejo de las herramientas informáticas que se utilizan en campus virtual de la asignatura, las redes sociales y/o profesionales son las herramientas más usadas por los alumnos, aunque solo un $12,1 \%$ de los alumnos se califica como usuario experto y un $20,7 \%$ no las usa nunca. Las wikis son las herramientas menos conocidas, ya que un $60,3 \%$ de los alumnos las desconocía y un $24,1 \%$ a pesar de conocerlas nunca las había usado.

Cabe desatacar que el uso de los foros de debate no está tan extendido como se pudiera presuponer, ya que un $50 \%$ de los usuarios no los utilizaban con anterioridad al curso. Algo parecido sucede con las videoconferencias, un 51,7\% nunca había usado este tipo de herramienta. Sin embargo, los cuestionarios online son las herramientas más utilizadas, solo un $32,8 \%$ de los encuestados no las había usado antes.

\begin{tabular}{|l|l|l|l|l|l|}
\hline $\begin{array}{l}\text { Herramienta } \\
\text { campus virtual }\end{array}$ & No lo conocía & No lo usaba & $\begin{array}{l}\text { lo usaba en } \\
\text { ocasiones }\end{array}$ & $\begin{array}{l}\text { lo usaba } \\
\text { habitualmente } \\
\text { pero no era } \\
\text { usuario/a } \\
\text { experto/a }\end{array}$ & $\begin{array}{l}\text { era } \\
\text { usuario/a } \\
\text { experto/a }\end{array}$ \\
\hline Wikis & $\mathbf{6 0 , 3 \%}$ & $24,1 \%$ & $10,3 \%$ & $3,4 \%$ & $1,7 \%$ \\
\hline Foros de debate & $19,0 \%$ & $\mathbf{3 1 , 0 \%}$ & $32,8 \%$ & $12,1 \%$ & $5,2 \%$ \\
\hline Videoconferencias & $10,3 \%$ & $\mathbf{4 1 , 4 \%}$ & $31,0 \%$ & $13,8 \%$ & $3,4 \%$ \\
\hline Cuestionarios online & $8,6 \%$ & $25,9 \%$ & $\mathbf{3 9 , 7 \%}$ & $24,1 \%$ & $3,4 \%$ \\
\hline $\begin{array}{l}\text { Redes sociales/ } \\
\text { redes profesionales }\end{array}$ & $1,7 \%$ & $20,7 \%$ & $37,9 \%$ & $27,6 \%$ & $\mathbf{1 2 , 1 \%}$ \\
\hline
\end{tabular}

Tabla 6. Nivel de pericia previa en el uso de herramientas del Campus Virtual

Para analizar la percepción que tienen los alumnos que han respondido al cuestionario en relación con la utilidad de los foros de dudas y las salas de trabajo, primero es necesario comprobar si existen diferencias estadísticamente significativas entre los estudiantes encuestados de los grupos online y semipresencial. Para ello se realiza la prueba paramétrica de Kruskal-Wallis (Tabla 8) con el programa estadístico SPSS (IBM, 2016) ya que no se cumple el supuesto de normalidad (Tabla 7) al realizar la prueba de Shapiro-Wilk $(\mathrm{N}<50$, sig. $=\mathrm{p}<0,05)$.

\begin{tabular}{|c|c|c|c|c|}
\hline \multirow{2}{*}{\multicolumn{2}{|c|}{$\begin{array}{l}\text { Grupos Online Octubre 2014-2015 (O014-15), } \\
\text { Online Diciembre 2014-2015(OD14-15) y } \\
\text { Semipresencial Octubre 2014-2015 (S14-15) }\end{array}$}} & \multicolumn{3}{|c|}{ Shapiro-Wilk } \\
\hline & & Estadístico & $\begin{array}{c}\text { Grados de } \\
\text { libertad }\end{array}$ & Sig. \\
\hline \multirow{2}{*}{$\begin{array}{l}\text { Las dudas que mis compañeros } \\
\text { han compartido en los foros me } \\
\text { han servido para aprender y }\end{array}$} & OO14-15 & 0,72 & 28 & 0,00 \\
\hline & OD14-15 & 0,58 & 14 & 0,00 \\
\hline
\end{tabular}

Desarrollo de competencias digitales en docencia online: la asignatura Cimientos del curso de adaptación a grado en ingeniería de edificación. María Dolores Vivas Urías, Silvia Andrés Ortega y Miguel Gómez Navarro. 


\begin{tabular}{|c|c|c|c|c|}
\hline \multirow{2}{*}{\multicolumn{2}{|c|}{$\begin{array}{c}\text { Grupos Online Octubre 2014-2015 (OO14-15), } \\
\text { Online Diciembre 2014-2015(OD14-15) y } \\
\text { Semipresencial Octubre 2014-2015 (S14-15) }\end{array}$}} & \multicolumn{3}{|c|}{ Shapiro-Wilk } \\
\hline & & Estadístico & \multirow{2}{*}{$\begin{array}{c}\text { Grados de } \\
\text { libertad } \\
15\end{array}$} & \multirow{2}{*}{$\begin{array}{l}\text { Sig. } \\
0,00\end{array}$} \\
\hline profundizar en la asignatura. & S14-15 & 0,75 & & \\
\hline \multirow{3}{*}{$\begin{array}{l}\text { Los mensajes publicados en el } \\
\text { foro de noticias refuerzan el } \\
\text { sentimiento de pertenencia a la } \\
\text { comunidad universitaria. }\end{array}$} & OO14-15 & 0,81 & 28 & 0,00 \\
\hline & OD14-15 & 0,76 & 14 & 0,00 \\
\hline & S14-15 & 0,80 & 15 & 0,00 \\
\hline \multirow{3}{*}{$\begin{array}{l}\text { Los recordatorios semanales } \\
\text { publicados en el foro general por } \\
\text { la profesora son útiles para no } \\
\text { perder el ritmo de realización de } \\
\text { actividades. }\end{array}$} & OO14-15 & 0,76 & 28 & 0,00 \\
\hline & OD14-15 & 0,64 & 14 & 0,00 \\
\hline & S14-15 & 0,74 & 15 & 0,00 \\
\hline
\end{tabular}

Tabla 7. Prueba de normalidad Shapiro-Wilk para la percepción sobre la utilidad de los foros.

Como sig. $=\mathrm{p}>0,05$ (Tabla 8), no existen diferencias estadísticamente significativas entre la percepción de los estudiantes encuestados de los grupos online y semipresencial acerca de la utilidad de los foros.

\begin{tabular}{|l|c|c|}
\hline \multicolumn{1}{|c|}{ Indicadores } & Chi-cuadrado & Sig. asintótica \\
\hline $\begin{array}{l}\text { Las dudas que mis compañeros han compartido en los } \\
\text { foros me han servido para aprender y profundizar en la } \\
\text { asignatura. }\end{array}$ & 1,54 & 0,46 \\
\hline $\begin{array}{l}\text { Los mensajes publicados en el foro de noticias refuerzan } \\
\text { el sentimiento de pertenencia a la comunidad } \\
\text { universitaria. }\end{array}$ & 0,98 & 0,61 \\
\hline $\begin{array}{l}\text { Los recordatorios semanales publicados en el foro general } \\
\text { por la profesora son útiles para no perder el ritmo de } \\
\text { realización de actividades. }\end{array}$ & 1,11 & 0,57 \\
\hline
\end{tabular}

Tabla 8. Estadísticos de la prueba no paramétrica de Kruskal-Wallis para la utilidad de los foros.

Más del $90 \%$ de los estudiantes que han participado en la encuesta está de acuerdo en que los foros ayudan a resolver dudas sobre los contenidos y/o actividades, en que las dudas que sus compañeros han compartido en los foros les han servido para aprender y profundizar, y en que los recordatorios semanales publicados en el Foro General son útiles para no perder el ritmo de realización de actividades (Tabla 9). Un porcentaje algo menor, un 88,0\% está de acuerdo en que los mensajes publicados en el Foro de Noticias refuerzan el sentimiento de pertenencia a la comunidad universitaria.

\begin{tabular}{|l|c|c|c|c|c|c|}
\hline \multicolumn{1}{|c|}{ Indicadores } & $\mathbf{1}$ & $\mathbf{2}$ & $\mathbf{3}$ & $\mathbf{4}$ & Media & DE \\
\hline $\begin{array}{l}\text { Los Foros de dudas de las unidades me ha ayudado a } \\
\text { resolver dudas sobre los contenidos y/ o actividades }\end{array}$ & $1,72 \%$ & $5,17 \%$ & $37,93 \%$ & $55,17 \%$ & 3,46 & 0,68 \\
\hline
\end{tabular}

Desarrollo de competencias digitales en docencia online: la asignatura Cimientos del curso de adaptación a grado en ingeniería de edificación. María Dolores Vivas Urías, Silvia Andrés Ortega y Miguel Gómez Navarro. 


\begin{tabular}{|l|c|c|c|c|c|c|}
\hline \multicolumn{1}{|c|}{ Indicadores } & $\mathbf{1}$ & $\mathbf{2}$ & $\mathbf{3}$ & $\mathbf{4}$ & Media & DE \\
\hline $\begin{array}{l}\text { Las dudas que mis compañeros han compartido en los } \\
\text { foros me han servido para aprender y profundizar en la } \\
\text { asignatura }\end{array}$ & $1,72 \%$ & $6,9 \%$ & $31,03 \%$ & $60,34 \%$ & 3,50 & 0,71 \\
\hline $\begin{array}{l}\text { Los mensajes publicados en el foro de noticias refuerzan el } \\
\text { sentimiento de pertenencia a la comunidad universitaria }\end{array}$ & $1,72 \%$ & $10,34 \%$ & $48,28 \%$ & $39,66 \%$ & 3,26 & 0,71 \\
\hline $\begin{array}{l}\text { Los recordatorios semanales publicados en el foro general } \\
\text { por la profesora son útiles para no perder el ritmo de } \\
\text { realización de actividades }\end{array}$ & $0 \%$ & $5,17 \%$ & $44,83 \%$ & $50 \%$ & 3,45 & 0,59 \\
\hline $\begin{array}{l}\text { La dinámica de la asignatura potencia la relación con mis } \\
\text { compañeros }\end{array}$ & $1,72 \%$ & $17,24 \%$ & $51,72 \%$ & $29,31 \%$ & 3,09 & 0,73 \\
\hline
\end{tabular}

Tabla 9. Percepción sobre la utilidad de los foros que tienen los alumnos del curso 2014-2015 (1=en total desacuerdo, 2=en desacuerdo, 3=de acuerdo, 4=totalmente de acuerdo, DE=desviación estandar)

Para analizar la percepción que tienen los alumnos que han respondido al cuestionario en relación con la utilidad de las wikis, es necesario comprobar si existen diferencias estadísticamente significativas entre los estudiantes encuestados de los grupos online y semipresencial para lo que se realiza la prueba no paramétrica de Kruskal-Wallis (Tabla 11) ya que no se cumple el supuesto de normalidad ( sig. $=\mathrm{p}<0,05$, Tabla 10)

\begin{tabular}{|c|c|c|c|c|}
\hline \multirow{2}{*}{\multicolumn{2}{|c|}{$\begin{array}{c}\text { Grupos Online Octubre 2014-2015 (O014-15), Online } \\
\text { Diciembre 2014-2015(OD14-15) y Semipresencial } \\
\text { Octubre 2014-2015 (S14-15) }\end{array}$}} & \multicolumn{3}{|c|}{ Shapiro-Wilk } \\
\hline & & Estadístico & Grados de & Sig. \\
\hline \multirow{3}{*}{$\begin{array}{l}\text { Me han ayudado a fijar los } \\
\text { contenidos de las distintas } \\
\text { unidades. }\end{array}$} & OO14-15 & 0,79 & 28 & 0,00 \\
\hline & OD14-15 & 0,65 & 14 & 0,00 \\
\hline & S14-15 & 0,71 & 15 & 0,00 \\
\hline \multirow{3}{*}{$\begin{array}{l}\text { Me han permitido poner en } \\
\text { práctica y reforzar lo estudiado en } \\
\text { la asignatura. }\end{array}$} & OO14-15 & 0,75 & 28 & 0,00 \\
\hline & OD14-15 & 0,62 & 14 & 0,00 \\
\hline & S14-15 & 0,69 & 15 & 0,00 \\
\hline \multirow{3}{*}{$\begin{array}{l}\text { Me han ayudado a profundizar en } \\
\text { la asignatura, gracias a la } \\
\text { interacción con mis compañeros. }\end{array}$} & OO14-15 & 0,79 & 28 & 0,00 \\
\hline & OD14-15 & 0,77 & 14 & 0,00 \\
\hline & S14-15 & 0,78 & 15 & 0,00 \\
\hline \multirow{3}{*}{$\begin{array}{l}\text { Me han ayudado a profundizar en } \\
\text { la asignatura, gracias a la } \\
\text { interacción con la profesora. }\end{array}$} & OO14-15 & 0,79 & 28 & 0,00 \\
\hline & OD14-15 & 0,65 & 14 & 0,00 \\
\hline & S14-15 & 0,77 & 15 & 0,00 \\
\hline
\end{tabular}

Tabla 10. Prueba de normalidad Shapiro-Wilk acerca de la percepción de la utilidad de las wikis.

Desarrollo de competencias digitales en docencia online: la asignatura Cimientos del curso de adaptación a grado en ingeniería de edificación. María Dolores Vivas Urías, Silvia Andrés Ortega y Miguel Gómez Navarro. 


\begin{tabular}{|l|c|c|}
\hline \multicolumn{1}{|c|}{ Indicadores } & Chi-cuadrado & Sig. asintótica \\
\hline Me han ayudado a fijar los contenidos de las distintas unidades. & 2,36 & 0,31 \\
\hline $\begin{array}{l}\text { Me han permitido poner en práctica y reforzar lo estudiado en la } \\
\text { asignatura. }\end{array}$ & 3,79 & 0,15 \\
\hline $\begin{array}{l}\text { Me han ayudado a profundizar en la asignatura, gracias a la } \\
\text { interacción con mis compañeros. }\end{array}$ & 5,04 & 0,08 \\
\hline $\begin{array}{l}\text { Me han ayudado a profundizar en la asignatura, gracias a la } \\
\text { interacción con la profesora. }\end{array}$ & 3,69 & 0,16 \\
\hline
\end{tabular}

Tabla 11. Estadísticos de la prueba no paramétrica de Kruskal-Wallis acerca de la utilidad de las wikis.

Como sig. $=\mathrm{p}>0,05$ (Tabla 11), no existen diferencias estadísticamente significativas entre la percepción de los estudiantes encuestados de los grupos online y semipresencial acerca de la utilidad de los wikis.

La mayoría de los participantes en la encuesta está de acuerdo en que las Wikis ayudan a fijar los contenidos de las unidades y permiten poner en práctica y reforzar lo estudiado (un $89,7 \%$ y un $93,1 \%$ respectivamente) (Tabla 12 ).

\begin{tabular}{|c|c|c|c|c|c|c|}
\hline Indicadores & 1 & 2 & 3 & 4 & Media & DE \\
\hline Ayudan a fijar los contenidos de las unidades & $5,17 \%$ & $5,17 \%$ & $43,1 \%$ & $46,55 \%$ & 3,31 & 0,8 \\
\hline Permiten poner en práctica y reforzar lo estudiado & $5,17 \%$ & $1,72 \%$ & $44,83 \%$ & $48,28 \%$ & 3,36 & 0,76 \\
\hline $\begin{array}{l}\text { Ayudan a profundizar en la asignatura, gracias a la } \\
\text { interacción con mis compañeros }\end{array}$ & $5,17 \%$ & $10,34 \%$ & $53,45 \%$ & $31,03 \%$ & 3,10 & 0,78 \\
\hline $\begin{array}{l}\text { Ayudan a profundizar en la asignatura, gracias a la } \\
\text { interacción con la profesora }\end{array}$ & $3,45 \%$ & $6,9 \%$ & $51,72 \%$ & $37,93 \%$ & 3,24 & 0,73 \\
\hline Las salas de trabajo son útiles para trabajar en equipo & $3,45 \%$ & $20,69 \%$ & $50 \%$ & $25,86 \%$ & 2,98 & 0,78 \\
\hline $\begin{array}{l}\text { El trabajo en equipo anima a mantenerse al día con la } \\
\text { asignatura }\end{array}$ & $5,17 \%$ & $6,9 \%$ & $41,38 \%$ & $46,55 \%$ & 3,29 & 0,82 \\
\hline
\end{tabular}

Tabla 12. Percepción sobre la utilidad de los wikis que tienen los alumnos del curso 2014-2015(1=en total desacuerdo, 2=en desacuerdo, 3=de acuerdo, 4=totalmente de acuerdo, DE=desviación estandar)

Más de un $80 \%$ está de acuerdo en que ayudan a profundizar en la asignatura gracias a la interacción con el resto de compañeros y con la profesora, y en que el trabajo en equipo anima a mantenerse al día con la asignatura.

Desarrollo de competencias digitales en docencia online: la asignatura Cimientos del curso de adaptación a grado en ingeniería de edificación. María Dolores Vivas Urías, Silvia Andrés Ortega y Miguel Gómez Navarro. 


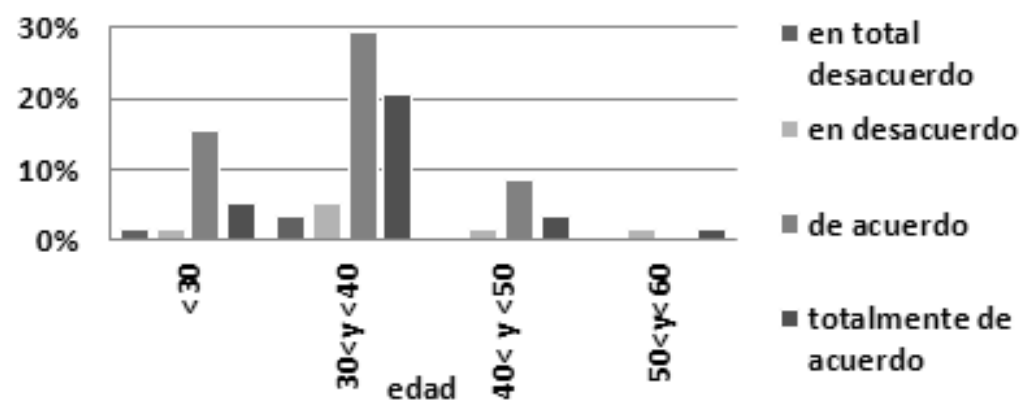

Figura 7. Influencia de la edad en la percepción sobre utilidad de las wikis como elemento que ayuda a profundizar en la asignatura, gracias a la interacción con los compañeros

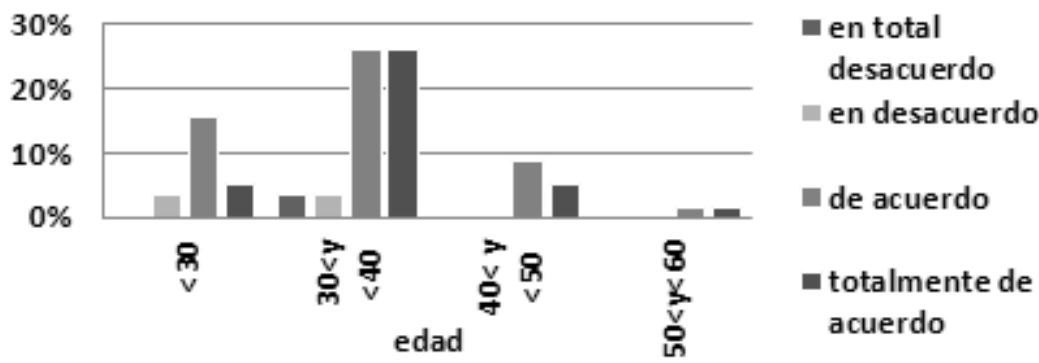

Figura 8. Influencia de la edad en la percepción sobre utilidad de las wikis como elemento que ayuda a profundizar en la asignatura, gracias a la interacción con el profesor

La percepción de la utilidad de las wikis como elemento que ayuda a profundizar en la asignatura, gracias a la interacción con los compañeros (Figura 7) y gracias a la interacción con el profesor (Figura 8) no depende de la edad.

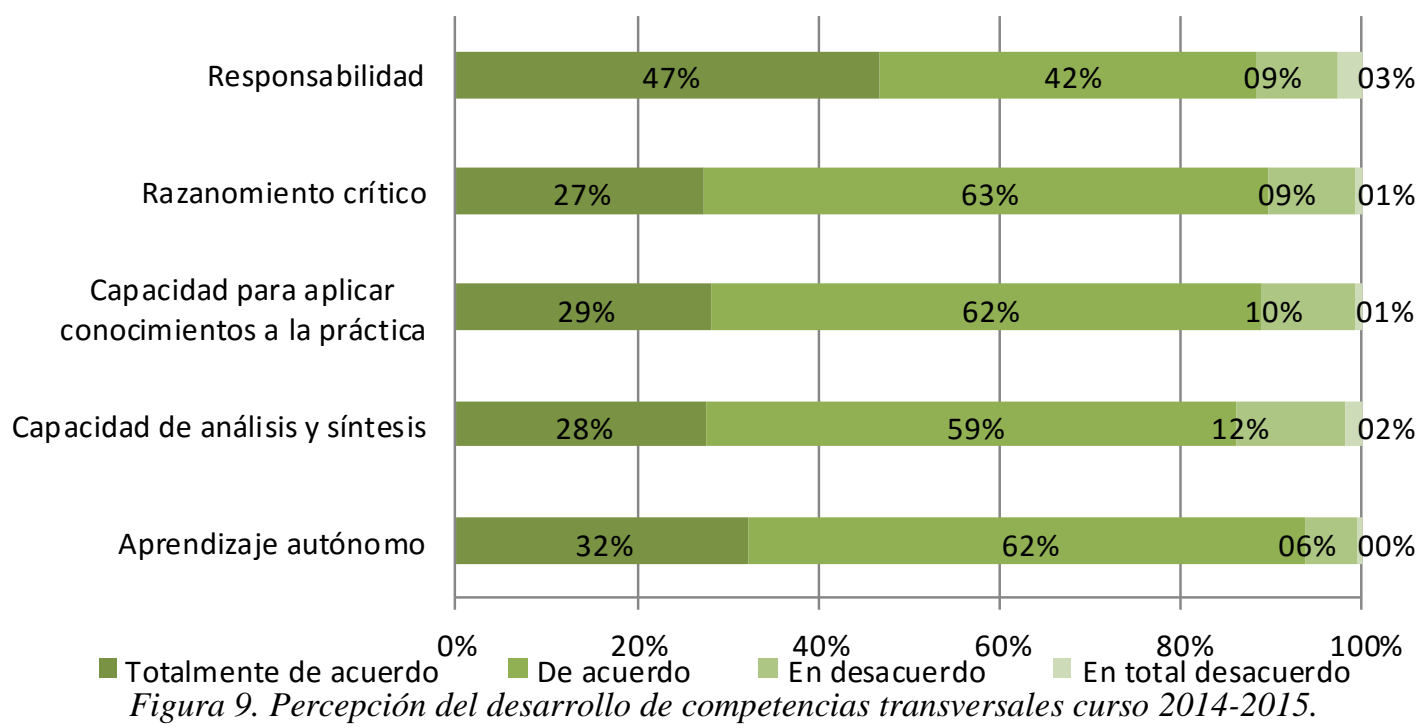

Respecto a la percepción que tienen los alumnos encuestados sobre el desarrollo en la asignatura Cimientos de competencias transversales como la responsabilidad, el razonamiento crítico, la capacidad para aplicar conocimientos a la práctica, la capacidad de análisis y síntesis y el aprendizaje autónomo, más del 86,1\% está de acuerdo con haberlas desarrollado (Figura 9).

Desarrollo de competencias digitales en docencia online: la asignatura Cimientos del curso de adaptación a grado en ingeniería de edificación. María Dolores Vivas Urías, Silvia Andrés Ortega y Miguel Gómez Navarro. 


\section{Conclusiones y limitaciones del estudio}

A la luz de los resultados, y teniendo en cuenta que el tamaño de muestra es inferior al deseado, ya que con un nivel de confianza del $95 \%$ en la estimación el margen de error es del 9,3\% (Bartlett, Kotrlik y Higgins, 2001; Cochran, 1977), y además no se ha llevado a cabo un muestreo probabilístico, los resultados obtenidos del análisis se considerarán como orientativos de la población de estudio.

La mayoría de los estudiantes encuestados están de acuerdo en que:

- los mensajes publicados en el Foro de Noticias refuerzan el sentimiento de pertenencia a la comunidad universitaria.

- los recordatorios semanales publicados en el Foro General son útiles para no perder el ritmo de realización de actividades.

- los foros de dudas ayudan a resolver dudas sobre los contenidos y/o actividades.

- las dudas que sus compañeros han compartido en los foros les han servido para aprender y profundizar.

- las wikis ayudan a profundizar en la asignatura gracias a la interacción con el resto de compañeros y con la profesora.

- el trabajo en equipo anima a mantenerse al día con la asignatura.

- la dinámica de la asignatura potencia la relación con el resto de los compañeros.

Cabe destacar que aunque más de la mitad de los alumnos había realizado algún curso a distancia con anterioridad al estudio de la asignatura, la mayoría de los estudiantes desconocía las herramientas wiki y más de la mitad no habían usado nunca foros de debates ni herramientas de videoconferencia.

Si tenemos en cuenta la rúbrica propuesta por Punie \& Brečko (2013) para las áreas de competencia comunicación (comunicar en entornos digitales, compartir recursos a través de herramientas en línea, conectar y colaborar con otros a través de herramientas digitales, interactuar y participar en comunidades y redes) y creación de contenido (crear y editar contenidos nuevos, integrar y reelaborar conocimientos y contenidos previos, saber aplicar los derechos de propiedad intelectual y las licencias de uso) de la competencia digital (Tabla 1), estos resultados parecen indicar que el uso de las herramientas del Campus Virtual por parte de los estudiantes del CAGIE, tanto en la realización de actividades como en la interacción estudiante-estudiante y estudianteprofesor, contribuye fundamentalmente al desarrollo de estas dos de áreas respecto a las siguientes competencias:

- 2.1 Interacción mediante nuevas tecnologías.

- 2.2 Compartir información y contenidos.

- 2.3 Participación ciudadana en línea.

- 2.4 Colaboración mediante canales digitales.

- 2.5 Netiqueta.

- 3.1 Desarrollo de contenidos.

- 3.2 Integración y reelaboración.

- 3.3 Derechos de autor y licencias.

Desarrollo de competencias digitales en docencia online: la asignatura Cimientos del curso de adaptación a grado en ingeniería de edificación. María Dolores Vivas Urías, Silvia Andrés Ortega y Miguel Gómez Navarro.

Página 23 de 29 
Además, la mayoría de los estudiantes encuestados creen haber desarrollado durante el estudio de la asignatura competencias transversales como la responsabilidad, el razonamiento crítico, la capacidad para aplicar conocimientos a la práctica, la capacidad de análisis y síntesis, y el aprendizaje autónomo.

Se puede concluir por tanto que en el campus virtual de la asignatura Cimientos el docente es un facilitador del aprendizaje y el enfoque de actividades consiste en formar parte de una comunidad de práctica, recibiendo y contribuyendo al mismo tiempo en el proceso de aprendizaje, para lo que el uso de las herramientas TIC es indispensable.

Presentación del artículo: 30 de noviembre de 2015

Fecha de aprobación: 26 de abril de 2016

Fecha de publicación: 30 de abril de 2016

Vivas-Urías, M.D., Andrés-Ortega, S. y Gómez-Navarro, M. (2016). Desarrollo de competencias digitales en docencia online: la asignatura Cimientos del curso de adaptación a grado en ingeniería de edificación. RED. Revista de Educación a Distancia. 49(8). Consultado el (dd/mm/aaaa) en http://www.um.es/ead/red/49

\section{Referencias}

Alaminos, A., Castejón, J. L. (2006). Elaboración, análisis e interpretación de encuestas, cuestionarios de escalas de opinión. Alicante, Marfil.

Anderson, T., Garrison, D.R. (1998). Learning in a Networked World: New Rules and Responsibilities. In C. Gibson (Ed). Distance Learners in Higher Education: Institutional responses for quality outcomes. Madison, Atwood. ISBN: 9781891859236

Anderson, J.; Van Weert, T. (2002). Information and communication Technologies in teacher education: A curriculum for schools and Programme of teacher development. UNESCO. Retrieved 04 13, 2016 from http://unesdoc.unesco.org/images/0012/001295/129538e.pdf

Baker, C. (2010). The Impact of Instructor Immediacy and Presence for Online Student Affective Learning, Cognition, and Motivation. Journal of Educators Online, 7(1).

Barberà, E. (2006). Aportaciones de la tecnología a la e-Evaluación. RED. Revista de Educación a Distancia, número especial VI. Recuperado el 04/02/2016 de http://revistas.um.es/red/article/download/24301/23641

Bartlett, J.E., Kotrlik, J. W, Higgins, C.C. (2001). Organizational research: Determining appropriate sample size in survey research appropriate sample size in survey research. Information technology, learning, and performance journal, 19(1), 43.

Desarrollo de competencias digitales en docencia online: la asignatura Cimientos del curso de adaptación a grado en ingeniería de edificación. María Dolores Vivas Urías, Silvia Andrés Ortega y Miguel Gómez 
Bawden, D. (2002). Revisión de los conceptos de alfabetización informacional y alfabetización digital. Anales de documentación, 5, 361-408.

Bawden, D. (2008). Origins and concepts of digital literacy. New York: Peter Lang

Bennett, S., Maton, K., Kervin, L. (2008). The 'digital natives' debate: a critical review of the evidence. British Journal of Educational Technology, 39, 5, 775-786.

Bereiter, C., Scardamalia, M. (1994). Computer support for knowledge building communities. Journal of the Learning Sciences, 3, 235-2283.

Blanco, A. (Coord.)(2009). Desarrollo y evaluación de competencias en educación superior . Narcea Ediciones.

Brown, C., Czerniewicz, L. (2010). Debunking the "digital native": beyond digital apartheid, towards digital democracy. Journal of Computer Assisted Learning, 26(5), 357-369.

Bullen, M., Morgan, T. (2011). Digital Learners not Digital Natives. La Cuestión Universitaria, 7, 60-68.

Bruffee, K. (1993). A Short Course in Writing: Composition, Collaborative Learning, and Constructive Reading. Harper Collins College Publishers.

Calvani, A., et al. (2009). Models and instruments for assessing digital competence at school. Journal of E-learning and Knowledge Society, 4(3).

Castaño, E., \& Garín, A. (2012). Incorporación de personas adultas a los estudios universitarios: Aprendizaje permanente para arquitectos técnicos. Formación universitaria, 5(3), 17-26.

Centeno, G., Cubo, S. (2013). Evaluación de la competencia digital y las actitudes hacia las TIC del alumnado universitario. Revista de Investigación Educativa, 31 (2), 517-536.

Cobo, C., Pardo, H. (2007). Planeta Web 2.0. Inteligencia colectiva o medios fast food. Barcelona: UVIC / México DF: FLACSO.

Cobo, C. (2012). Skills for Innovation: Envisioning an Education that Prepares for Changing World. University of Oxford,Oxford Internet Institute. Curriculum Journal, 0, p. 1-19. DOI: 10.1080/09585176.2012.744330.

Cochran, W. G. (1977). Sampling techniques (3rd Ed). New York, John Wiley \& Sons

Corrin, L., Lockyer, L., \& Bennett, S. (2010). Technological diversity: An investigation of student's technology use in everyday life and academic study. Learning, Media and Technology, 35(4), 387-401

Desarrollo de competencias digitales en docencia online: la asignatura Cimientos del curso de adaptación a grado en ingeniería de edificación. María Dolores Vivas Urías, Silvia Andrés Ortega y Miguel Gómez Navarro. 
Crook, C. (1998). Ordenadores y aprendizaje colaborativo. Madrid, Ministerio de Educación y Ciencia-Ediciones Morata.

Cruz, A., Lara, P., \& Redondo, S. (2010). Un modelo pedagógico para el proyecto UEM Personal. Actas de las VII Jornadas Internacionales de Innovación Universitaria, Universidad Europea de Madrid. Recuperado el 04/02/2016 de http://universidadeuropea.es/myfiles/pageposts/jiu/jiu2010/pdf/96c.pdf

Davidson-Shivers, G. V. (2009). Frequency and types of instructor interactions in online instruction. Journal of Interactive Online Learning, 8(1), 23-40.

Engeström, Y. (1992). Interactive Expertise: Studies in Distributed Working Intelligence. Department of Education, University of Helsinki.

Esteve, F., Gisbert, M. (2013). Competencia digital en la educación superior: instrumentos de evaluación y nuevos entornos. Enl@ce Revista Venezolana de Información, Tecnología y Conocimiento, 10 (3), 29-43.

European Parliament and the Council. (2006). Recommendation of the European Parliament and of the Council of 18 December 2006 on key competences for lifelong learning. Official Journal of the European Union, L394/310.

Ferrari, A. (2012). Digital Competence in practice: An analysis of frameworks.Sevilla: JRC IPTS.(DOI: 10.2791/82116).

Gallardo, E. E. (2012). Hablemos de estudiantes digitales y no de nativos digitales. Universitas Tarraconensis. Revista de Ciències de l'Educació, 1(1), 7-21.

Garland, R. (1991). The mid-point on a rating scale: Is it desirable. Marketing bulletin, 2(1), 66-70.

Gibbons, M., et al. (1994). The New Production of Knowledge. The Dynamics of Science and Research in Contemporary Societies. London, SAGE Publications.

Gisbert, M.; Espuny Vidal C., \& González, J. (2011). INCOTIC. Una herramienta para la@utoevaluación diagnóstica de la competencia digital en la universidad. Profesorado: revista de currículum y formación de profesorado, 15(1), 76-89.

Gómez, M., et al. (2015). Propuesta de herramienta de evaluación de competencias específicas. Actas de las XII Jornadas Internacionales de Innovación Universitaria, Universidad Europea de Madrid. Recuperado el 08/22/2015 de http://universidadeuropea.es/myfiles/pageposts/jiu/jiiu2015/index.html

Gros, B., Contreras, D. (2006). La alfabetización digital y el desarrollo de competencias ciudadanas. Revista Iberoamericana de Educación (OEI), 42, 103-125.

Desarrollo de competencias digitales en docencia online: la asignatura Cimientos del curso de adaptación a grado en ingeniería de edificación. María Dolores Vivas Urías, Silvia Andrés Ortega y Miguel Gómez Navarro. 
Hernández, N., González, M., Muñoz, P. (2014). La planificación del aprendizaje colaborativo en entornos virtuales. Comunicar: Revista Científica de Comunicación y Educación, 21(42), 25-33.

Hunter, B. (1983). My students use computers: learning activities for computer literacy. Reston, Reston Publishing.

IBM (2016). Recuperado el 04/13/2016 de http://www-01.ibm.com/software/es/ analytics/spss/products/statistics/

Katz, I. R. (2007). Testing information literacy in digital environments: ETS's iSkills assessment. Information technology and Libraries, 26(3), 3.

Kennedy, G., et al. (2008). First year students' experiences with technology: are they really digital natives? Australasian Journal of Educational Technology, 24(1), 108122.

Kerlinger, F. N., Lee, H. B.(1964). Foundations of behavioral research: Educational and psychological inquiry. New York: Holt, Rinehart and Winston.

Kirschner, F.; Paas, F.; Kirschner, P.A. (2008). A cognitive load approach to collaborative learning: United brains for complex tasks. Educational Psychology Review, (21), 3142.

Knowles, M.S. (1980). The modern practice of adult education: from pedagogy to andragogy. New York: Cambridge: The Adult Education Company. ISBN: 0695 81472 9. Recuperado el 09/09/2015 de http://www.umsl.edu/ henschkej/articles/a_The_\%20Modern_Practice_of_Adult_Ed ucation.pdf

Lancaster, L.C, \& Stillman, D. (2002). When generations collide. Who they are. Why they clash. How to solve the generational puzzle at work. New York, Collins Business.

Learreta, B., Cruz, A., \& Benito, A. (2012). Análisis documental sobre el estudiante adulto en la Educación Superior: un perfil emergente de alumnado. Revista Iberoamericana de Educación, 58, 1-12.

Likert, R. (1932). A technique for the measurement of attitudes. Archives of psychology, (140), 5-55.

MECD y OCDE (2003). Los desafíos de las tecnologías de la información y las comunicaciones en la educación. Madrid, MECD.

Nolasco, P., Ojeda, M. M. (2016). La evaluación de la integración de las TIC en la educación superior: fundamento para una metodología. RED-Revista de Educación a Distancia, (48).

Desarrollo de competencias digitales en docencia online: la asignatura Cimientos del curso de adaptación a grado en ingeniería de edificación. María Dolores Vivas Urías, Silvia Andrés Ortega y Miguel Gómez Navarro. 
Prensky, M. (2010). Teaching Digital Natives: Partnering for Real Learning. London, Corwin.

Punie, Y., \& Brečko, B. N. (Eds.). (2013). DIGCOMP: A framework for developing and understanding digital competence in Europe.

Redecker, C., et al. (2010). The future of learning: New ways to learn new skills for future jobs. Results from an online expert consultation. Technical Note JRC60869, JRC-IPTS, Seville.

Redondo, S. (2012). Evaluación de la aplicación del modelo pedagógico UEM personal a estudios universitarios de grado y postgrado en modalidad online. Tesis Doctoral. Directora: Dra Águeda Benito Capa. Madrid: Universidad Europea de Madrid, Programa de Doctorado en Educación, Facultad de Ciencias Sociales.

Roschelle, J., Teasley, S. (1995). The construction of shared knowledge in collaborative problem solving. Computer Supported Collaborative Learning, p. 69-97. Springer Berlin Heidelberg. ISBN: 978-3-642-85100-1

Rué, J. (2007). Enseñar en la Universidad: El EEES como reto para la Educación Superior. Madrid, Narcea Ediciones.

Sfard, A. (1998). On two metaphors for learning and the dangers of choosing just one. Educational Researcher, 27(2), 4-13.

Survey Monkey (2015). Recuperado Portal Survey Monkey https://es.surveymonkey.com/mp/take-a-tour/?ut_source=heade

Tobón, S. (2006). Competencias, calidad y educación superior. Bogotá, Coop. Editorial Magisterio.

Velasco, P. M., García, M. J., \& Terrón, M. J. (2012). Guía para el diseño de recursos docentes que fomenten el desarrollo y evaluación de las competencias transversales en educación. Málaga: Vértice, 2012.

Waldegg, G. (2002). El uso de las nuevas tecnologías para la enseñanza y el aprendizaje de las ciencias. Revista electrónica de investigación educativa, 4(1).

White, D., Le Cornu, A. (2011). Visitors and residents: A new typology for online engagement. FirstMonday, 16(9).

Zapata, M. (2010). Estrategias de evaluación de competencias en entornos virtuales de aprendizaje. RED. Revista de Educación a Distancia. Sección de Docencia Universitaria en la Sociedad del Conocimiento. Número 1. Recuperado el 04/03/2016 en https://www.um.es/ead/reddusc/1/eval_compet.pdf

Desarrollo de competencias digitales en docencia online: la asignatura Cimientos del curso de adaptación a grado en ingeniería de edificación. María Dolores Vivas Urías, Silvia Andrés Ortega y Miguel Gómez Navarro. 
Zhao, Y. et al. (2005). What makes the difference? A practical analysis of research on the effectiveness of distance education. The Teachers College Record, 107(8), 18361884.

Desarrollo de competencias digitales en docencia online: la asignatura Cimientos del curso de adaptación a grado en ingeniería de edificación. María Dolores Vivas Urías, Silvia Andrés Ortega y Miguel Gómez Navarro. 